\title{
Sonic Hedgehog signaling pathway as a potential target to inhibit the progression of hepatocellular carcinoma (Review)
}

\author{
KUO-SHYANG JENG ${ }^{1,2}$, CHI-JUEI JENG ${ }^{3}$, WEN-JUEI JENG ${ }^{4}$, I-SHYAN SHEEN ${ }^{3}$, SHIH-YUN LI ${ }^{2}$, \\ CHUEN-MIIN LEU ${ }^{5}$, YEOU-GUANG TSAY ${ }^{6}$ and CHIUNG-FANG CHANG ${ }^{1,2}$ \\ Departments of ${ }^{1}$ General Surgery and ${ }^{2}$ Medical Research, Far Eastern Memorial Hospital, New Taipei City 22060; \\ ${ }^{3}$ Graduate Institute of Clinical Medicine, National Taiwan University, Taipei City 10617; \\ ${ }^{4}$ Department of Hepato-Gastroenterology, Chang-Gung Memorial Hospital, Linkou Medical Center, \\ Chang-Gung University, Taoyuan City 33305; Institutes of ${ }^{5}$ Microbiology and Immunology and \\ ${ }^{6}$ Biochemistry and Molecular Biology, National Yang-Ming University, Taipei City 11221, Taiwan, R.O.C.
}

Received November 9, 2018; Accepted August 6, 2019

DOI: $10.3892 / \mathrm{ol} .2019 .10826$

\begin{abstract}
Hepatocellular carcinoma (HCC) is one of the leading causes of cancer-associated mortality worldwide. Hepatocarcinogenesis involves numerous interlinked factors and processes, including the Sonic hedgehog (Shh) signaling pathway, which participates in the carcinogenesis, progression, invasiveness, recurrence and cancer stem cell maintenance of HCC. The Shh signaling pathway is activated by ligands that bind to their receptor protein, Protein patched homolog (Ptch). The process of Shh ligand binding to Ptch weakens the inhibition of smoothened homolog (SMO) and activates signal transduction via glioma-associated oncogene homolog (Gli) transcription factors. The overexpression of Shh pathway molecules, including Shh, Ptch-1, Gli and SMO has been indicated in patients with HCC. It has also been suggested that the Shh signaling pathway exhibits cross-talk between numerous other signaling pathways. The inactivation of the Shh signaling
\end{abstract}

Correspondence to: Dr Chiung-Fang Chang, Department of General Surgery, Far Eastern Memorial Hospital, 21, Sec. 2, Nanya South Road, Banqiao, New Taipei City 22060, Taiwan, R.O.C.

E-mail: cfchang.gina@gmail.com

Dr Chuen-Miin Leu, Institute of Microbiology and Immunology, National Yang-Ming University, 155, Sec. 2, Linong Street, Taipei City 11221, Taiwan, R.O.C.

E-mail:cmleu@ym.edu.tw

Abbreviations: HCC, hepatocellular carcinoma; Shh, Sonic Hedgehog; Ptch, Protein Patched homolog; SMO, Smoothened; Gli-1, glioma-associated oncogene homolog 1 ; HBV/HCV, hepatitis B or $\mathrm{C}$ viral; Hh, Hedgehog; Sufu, suppressor of fused homolog; EMT, epithelial-mesenchymal transition; MMP-9, metalloproteinase-9; SASH1, SAM- and SH3-domain containing 1; TGF, transforming growth factor; DEN, diethylnitrosamine; sFRP1, secreted frizzled related protein $1 ; \mathrm{MeCP} 2$, methyl- $\mathrm{CpG}$ binding protein 2

Key words: sonic hedgehog signaling pathway, hepatocellular carcinoma, recurrence, cancer stem cells pathway reduces $\mathrm{HCC}$ growth, increases radio-sensitivity and increases the beneficial effect of chemotherapy in HCC treatment. Therefore, inhibition of the Shh pathway may be an effective target therapy that can be used in the treatment of HCC.

\section{Contents}

1. Introduction

2. The Hedgehog signaling pathway

3. Overexpression of the Shh signal pathway in HCC is associated with a poor prognosis

4. Various factors activate the Shh pathway in HCC

5. Activation of the Shh pathway enhances hepatocarcinogenesis and HCC progression

6. Shh signaling pathway contributes to invasiveness, metastasis, and behavior of cancer stem cells

7. Shh signaling pathway cross-talks with other signaling pathways

8. Targeting the Shh signaling pathway as a promising treatment strategy

9. Conclusions and future direction

\section{Introduction}

Hepatocellular carcinoma (HCC) remains one of the leading causes of cancer-associated mortality worldwide, and involves numerous interlinked factors such as inflammation, hypoxia, immunity and processes from liver injury, liver cirrhosis to hepatocarcinogenesis (1). The well-established etiological factors include chronic hepatitis B or C viral (HBV/HCV) infection, excessive alcohol intake, non-alcoholic steatohepatitis and exposure to aflatoxin B (2-5). In Asia, the prevalence of HBV-infected HCC is 50-80\% from $2016(6,7)$. HBV/HCV infection can lead to apoptosis and immune cell infiltration, and can cause the induction of damaging inflammatory responses and repeated chronic tissue injury and repair, which results in the progression of $\mathrm{HCC}(8)$. 
Currently, the most effective treatments for HCC are hepatic resection or liver transplantation (9). However, less than $20 \%$ of patients with HCC can be treated surgically. Furthermore, the 5-year recurrence rates of HCC after surgical resection were $57-75 \%$ due to the limited efficacy of chemotherapy, radiation and target therapy (10). Consequently, there is an essential requirement for the development of improved therapeutic strategies that can be used to treat HCC. The investigation of the signaling pathways driving hepatocarcinogenesis could be helpful to identify novel targets for HCC treatment. Hedgehog (Hh) signaling pathway contributes to the progression of a variety of human cancer types, including HCC, breast cancer and basal cell carcinoma (11-14). The Hh pathway serves a crucial role in carcinogenesis, invasiveness, recurrence and cancer stem cell maintenance in HCC (12). In the current review, recent studies of investigating the Shh signaling pathway and its association with $\mathrm{HCC}$, were assessed.

\section{Hh signaling pathway}

Hh molecules are important soluble factors that regulate cell proliferation and differentiation during embryonic development, adult tissue homeostasis and carcinogenesis $(15,16)$. Molecules that are associated with $\mathrm{Hh}$ signaling were first identified in Drosophila, and later found to be highly conserved in higher organisms, including mammals (17). In human, three types of $\mathrm{Hh}$ ligands have been associated with this pathway, Sonic hedgehog (Shh), Indian hedgehog and Desert hedgehog. In the liver, $\mathrm{Hh}$ ligands generated by injured hepatocytes, activated hepatic stellate cells, progenitor cells, Kupffer cells, natural killer T cells and endothelial cells (18). Each Hh ligand exhibits a different spatial and temporal expression patterns (19). The roles of these ligands in cellular and developmental function has been previously reviewed (20). In the current review, the role of the Shh signaling pathway in HCC was evaluated. The Shh signaling pathway is activated when Shh ligands bind to their receptors, protein patched homolog (Ptch) 1 or $2(21,22)$. In the absence of Hh ligands, Ptch continuously inhibits the activity of G-protein-coupled receptor like receptor, SMO protein, in the Off stage (Fig. 1, left) (23). Suppressor of fused homolog (Sufu) is an important negative regulator of the Hh signaling pathway (24). Sufu sequesters glioma-associated oncogene homolog (Gli) transcription factors in the cytosol prior to pathway activation (25). The binding of Hh ligands to Ptch weakens the inhibition of SMO and promotes its translocation to the plasma membrane for complete activation. The activation of SMO results in the dissociation of the Gli-Sufu complex, and leads to the translocation of Gli protein to the nucleus (Fig. 1, right). There are three Gli family transcription factors: glioma-associated oncogene homolog 1 (GLI-1), GLI-2 and GLI-3 (26). Gli-1 and Gli-2 are transactivators and Gli-3 is a repressor. In the nucleus, the Gli proteins bind to the Gli-binding consensus sequence and upregulate the expression of target genes, including SNAIL, c-MYC, BCL-2 and Prominin-1 (CD133) (27).

\section{Overexpression of the Shh signaling pathway in HCC is associated with a poor prognosis}

The activation or overexpression of $\mathrm{Hh}$ molecules, including PTCH-1, GLI and SMO have been frequently indicated in HCC tissues (28-30). Che et al (28) analyzed 46 HCC tissues using reverse transcription-quantitative PCR (RT-qPCR) and identified numerous Hh signaling molecules that were expressed in $\geq 50 \%$ of tumors. Specifically, GLI- 1 expression was associated with disease-free and overall survival in patients with HCC. Therefore, GLI-1 expression may be a prognostic predictor of HCC. Another study used RT-qPCR to analyze 50 patients with $\mathrm{HCC}$ after surgical resection, and it was demonstrated that high $P T C H-1$ and $G L I-1$ expression increased the risk of post-section recurrence and was associated with poor overall survival (29). The results of this study indicated that higher $P T C H-1$ expression was associated with the early recurrence of HCC and may serve as a poor prognostic marker for the disease. Another study measured GLI-2 levels, using immunohistochemistry in 68 patients with HCC. The results revealed that the patients with increased GLI-2 expression exhibited earlier HCC recurrence, and presented with both shorter disease-free and overall survival times (31). In summary, these studies demonstrated that the activation of the Shh signaling pathway in patients with HCC was inversely associated with disease prognosis.

\section{Various factors activate the Shh pathway in HCC}

A number of studies have demonstrated that an association exists between the activation of the Shh signaling pathway and poor prognosis in patients with HCC. Therefore, it is important to understand how the pathway is activated. Adult healthy hepatocytes barely express Hh ligands, however, live epithelial cells begin to generate Hh ligands during injury or severe stress. The overexpression of Shh ligands and the concomitant expression in HCC tissues can activate the Shh signaling pathway $(28,32,33)$. In addition, viral infection and chronic inflammation play a critical role in the activation of the Shh signaling pathway. HBV DNA integrates into hepatocyte chromosomes. The expression of the $H B V$ gene product $H B x$ protein can increase $S H H, P T C H-1$ and $G L I-2$ expression, and is able to stabilize GLI-1 and GLI-2 proteins $(34,35)$. Hh signaling pathway activity has been indicated to be necessary for HBx transformation, as demonstrated by a study that showed that the administration of a SMO inhibitor reduced HCC growth in $\mathrm{HBx}$ transgenic mice (35). HBV/HCV infection has also been indicated to increase Hh ligands in hepatocytes and expand the Hh-responsive cells, which promote liver fibrosis and hepatocarcinogenesis (36). Chronic infection with HBV or HCV leads to continuous hepatocyte apoptosis, leukocyte infiltration and stimulates the Hh signaling pathway $(3,35,37)$. A novel mouse model has revealed that chronic or acute liver injury can induce the activation of the Hh pathway. In this aforementioned study, primary hepatocytes upregulated SMO expression during Fas-induced liver injury and this also increased Fas-induced apoptosis (38). Activation of the Hh pathway initiates downstream gene expression of cancer stem cell marker CD133 and cytokine IL-6, which serves an important role in the liver acute phase response and in HCC development (39-41). PTCH-1 has been revealed to regulate cell cycle progression and induce tumorigenicity (42). Inhibition of the Hh pathway can reduce PTCH-1-dependent tumor progression (43). In addition to viral infection, mutation of the Hh signaling pathway molecules can also activate the Hh pathway (14). In a number of patients with HCC, SMO mutation at the C-terminal lysine (K575M) was 


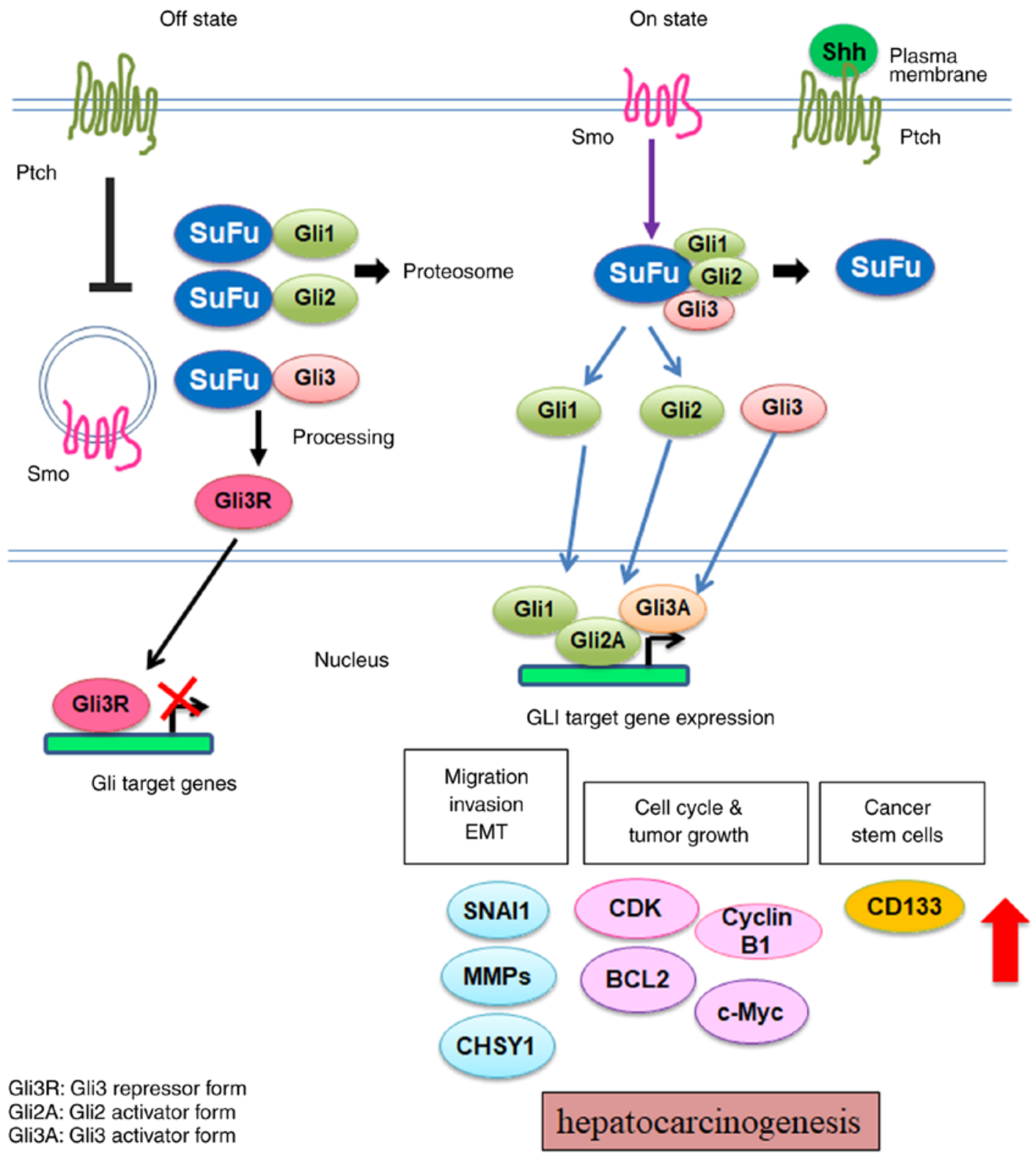

Figure 1. Shh signaling pathway in hepatocellular carcinoma. Left (Off state): Ptch inhibits SMO activation. The signaling from SMO to Gli is blocked. SuFu binds to Gli for protein degradation via the proteasome. Therefore, the expression of Hh signaling pathway target gene turns off. Right (On state): Shh ligand bind to their receptor, PTCH. The binding of Hh ligands to PTCH weakens the inhibition of SMO and activates signal transduction via GLI transcription factor, activating downstream gene expression in cell migration/invasion/transition (SNAIL, MMPs, CHSY1), cell cycle/tumor growth (cyclin B1, CDK, Bcl2) and cancer stem cell marker (CD133). Shh, Sonic hedgehog; Ptch, protein patched homolog; SMO, smoothened homolog; Gli, glioma associated oncogene homolog; EMT, epithelial-mesenchymal transition.

revealed to alter the binding between PTCH and SMO, alleviating SMO from PTCH inhibition and subsequently activating downstream signaling (44).

\section{Activation of the Shh pathway enhances hepatocarcino- genesis and HCC progression}

Accumulating evidence has demonstrated that an activated Shh pathway is associated with hepatocarcinogenesis $(11,12,32)$. The Shh pathway is activated in tumors and differentiates cancerous cells from the non-cancerous cells (45). In a transgenic mouse model, Shh expression in the liver was indicated to, not only induce liver fibrosis, but also enhance hepatocarcinogenesis (46). Activated Shh signaling increases cyclin B1 and cyclin-dependent kinase 1 (CDK1) protein expression, which facilitates the $\mathrm{G}_{2} / \mathrm{M}$ transition to promote cell proliferation and enhance hepatocarcinogenesis (47). In addition, the overexpression of $S M O$ and an increased ratio of $S M O$ to $P T C H$ mRNA expression is associated with tumor sizes in human HCC, and SMO-mediated c-Myc overexpression serves a crucial role in HCC development (32). SMO is an important regulator of adult liver repair due to its role in the promotion of epithelial-mesenchymal transition (EMT), and serves a key role in the early stages of HCC development (48). Lastly, GLI transcription factors are also involved in HCC formation. GLI-2 serves a dominant role over GLI-1 or GLI-3 in promoting HCC cell proliferation and survival (49). This is consistent with the observation that enhanced GLI-2 expression 
is associated with early recurrence and shorter survival in patients with HCC (31). Therefore, it can be suggested that the Shh signaling pathway is essential for the development and progression of HCC. Shh pathway may promote HCC growth via upregulating genes that promote cell cycle (CYCLINS, $C D K$ and $c-M Y C)$ and cell survival (BCL2).

\section{Activation of Shh signaling pathway contributes to} invasiveness, metastasis and behavior of cancer stem cells

In addition to inducing HCC growth, evidence has also demonstrated that an activated Shh signaling pathway is associated with HCC capsular/vascular invasion $(28,31)$. The Shh signaling pathway mediates HCC invasion and metastasis by upregulating matrix metalloproteinase-9 (MMP-9) (50). Bromodomain 4, which is a transcriptional and epigenetic regulator, enhances HCC cell migration and invasion through Shh signaling pathway-mediated MMP-2 and MMP-9 activation (51). The upregulation of GLI-1 expression in HCC tissues is associated with clinicopathological characteristics (52). Therefore, GLI-1 may participate in HCC progression and metastasis via the induction of EMT. Twist is a key transcriptional factor for EMT, which promotes the invasion and metastasis of tumor cells $(53,54)$. Increased Gli-1 and Twist expression has been observed in $\mathrm{HCC}$ tissues, indicating the possible involvement of the Shh pathway in EMT (55). The Shh pathway promotes HCC migration and invasion through activation of FAK and AKT, and the subsequent upregulation of MMP-2 and MMP-9 expression (56). Based on the available evidence, it can be concluded that the Shh pathway can regulate invasion, migration and EMT, at least in part, via regulating MMP expression.

SAM- and SH3-domain containing 1 (SASHI) is a tumor suppressor gene that belongs to the SLY family adaptor proteins (57). SASH1 may reduce cancer cell proliferation, migration and invasion (58). SASH1 has been demonstrated to downregulate the Shh-Gli-1 and PI3K-AKT pathways to inhibit $\mathrm{HCC}$ invasion and metastasis, underlying the importance of the Shh pathway in HCC progression (59). CHSY1 encodes for an enzyme that catalyzes the polymerization of chondroitin sulfate $(60,61)$. The overexpression of CHSY1 enhances HCC migration, invasion and EMT by promoting Shh binding and signaling (62). One study revealed that treatment with Vismodegib, a SMO inhibitor, decreased CHSY1-induced HCC cell migration, invasion, and lung metastasis (39). In summary, the Shh pathway regulates cell growth, and can contribute to the invasion and migration of HCC cells.

The Shh signaling pathway can influence the behaviors of cancer stem cells (63). Shh signaling pathway activation occurs in cancer stem cells $\left(\mathrm{CD}_{133^{+}}\right)$of mouse hepatoma cell line Hepa1-6. CD133+ HCC cells with upregulated SMO mRNA exhibit significantly higher colony proliferation and clonogenicity compared with that in CD133- HCC cells (64). However, whether the Shh pathway controls these behaviors in the cancer stem cells of human HCC, requires further investigation.

\section{Shh signaling pathway cross-talks with other signaling pathways}

Transforming growth factor (TGF)- $\beta$ serves a key role in the induction of EMT and its expression has been revealed to be elevated in $40 \%$ of human HCC tissues $(65,66)$. The activation of the Shh signaling pathway is frequently detected in HCC; therefore, the Shh signaling pathway may interact with TGF- $\beta$ signaling to enhance EMT in HCC (28). Using computational algorithms and confirmation of its presence in HCC cell lines, Steinway et al (67) demonstrated that TGF- $\beta$ induced the activation of Wnt and Shh signaling to regulate EMT in HCC. Furthermore, GLI-2 has been identified as a direct target of TGF- $\beta$ /SMAD signaling pathway in a variety of cell types, including fibroblasts, breast cancer cells and pancreatic carcinoma (68). GLI-2 expression is associated with the expression of active forms of SMADs in HCC tissues (67). Therefore, it can be suggested that TGF- $\beta$ may activate the Shh signaling pathway via upregulation of GLI-2. TGF- $\beta$ is significantly elevated with the active form of SMO in mouse keratinocytes, suggesting that the Hh pathway can increase TGF- $\beta$ expression (69). Therefore, the expression of Shh and TGF- $\beta$ signaling together, may amplify each other and participate in the invasion and metastasis of HCC.

In other varieties of primary and tumor cells, active $\mathrm{Hh}$ signaling has been demonstrated to induce EMT via WNT, EGF/FGF, Notch and TGF- $\beta$ signaling cascades (70). The $\mathrm{Wnt} / \beta$-catenin pathway is a well-known promoter of HCC development, and it is possible that this pathway cross-talks with the Shh signaling pathway to regulate HCC progression (71). A recent study demonstrated how the cross-talk between the $\mathrm{Hh}$ and Wnt pathway can contribute to HCC formation in a diethylnitrosamine (DEN) -administrated obese mouse model (72). In chronic fibrosis, upregulated Gli could target Myc to drive TGF- $\beta 2$ expression for Wnt5a secretion (72). Receptors for Wnt5a are highly expressed in mouse HCC and a number of poorly differentiated human cell lines (72). Furthermore, elevated Wnt5a expression has also been detected in poorly differentiated human HCC cells, suggesting that both $\mathrm{Hh}$ and Wnt ligands are able to function in an autocrine-positive feedback manner to maintain tumors (72). In the DEN-induced HCC model, Wnt signaling and Hh pathway activity increased during HCC development (73). An increased Gli-1 and Gli-2 expression is associated with an increase in Wnt pathway inhibitor-secreted frizzled related protein 1 (sFRP1) in HCC (73). It has also been found the upregulation of sFRP1 and Gli is present in patients with intermediate and advanced HCC (73).

\section{Targeting the Shh signaling pathway as a promising treatment strategy for HCC}

Accumulated evidence has demonstrated that the Shh pathway is associated with the growth, invasiveness, recurrence and cancer stem cell maintenance of HCC $(12,29,30)$. Therefore, inhibition of the Shh signaling pathway may be used as a potential HCC therapeutic strategy. The inhibition of Hh signaling may inhibit liver fibrosis and decrease cancer progenitors (74). Hh antagonist GDC-0449 and cyclopamine have been revealed to bind to SMO and inhibit the Shh signaling pathway $(75,76)$. In a HBx transgenic mouse model, the inhibition of the $\mathrm{Hh}$ signaling pathway by GDC-0449 delayed hepatocarcinogenesis (35). The results of previous studies showed that the SMO inhibitors cyclopamine and GDC-0449 reduced HCC growth and immune infiltration in vivo, and tumor size and Gli-1 


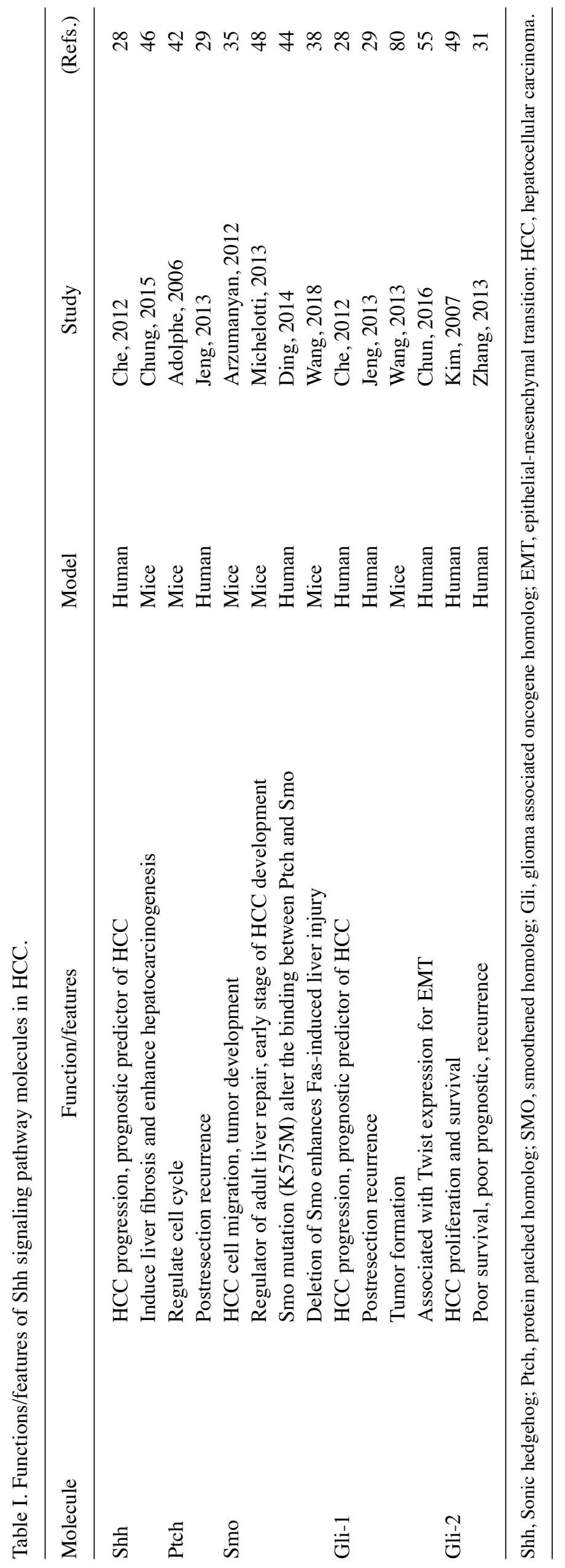


mRNA expression were significantly decreased (77,78). Thus, GDC-0449 treatment is effective in reducing HCC tumor sizes and the degree of cell infiltration (immune cell recruitment) in mouse models.

Gli may also be another therapeutic target. The inhibition of GLI-1 suppresses cell growth/cell cycle progression, induces apoptosis as well as autophagy via an Erk1/2 activity-dependent mechanism in human chondrosarcoma (79). Wang et al (80) revealed that the GLI inhibitor GANT61 inhibited tumor formation and decreased tumor sizes in a Huh7 xenograft model. The autophagy inhibitor, 3-MA, partially blocked this effect. Results of the aforementioned study suggested that inhibition of the Hh pathway may induce autophagy through the upregulation of $\mathrm{Bcl} 2$-interacting protein 3, which displaces Bcl 2 from Beclin-1 to induce apoptosis. Therefore, autophagy status is a crucial factor to determine the therapeutic responses to Hh-targeted therapies. Other inhibitors that target the $\mathrm{Hh}$ signaling pathway, including XL-139, IPI-926 and LDE-225, were tested in clinical trials (81).

Melittin, a bee venom, inhibits HCC cell proliferation by downregulating Methyl-CpG binding protein 2 (MeCP2) via the Shh signaling pathway (82). Melittin treatment may increase Ptch expression due to its induction of the demethylation of Ptch1 promoter, which is associated with the downregulation of MeCP2 (82). Furthermore, the downregulation of Shh and Gli-1 has also been revealed in Melittin treatment (82). In addition, the downregulation of Gli-1 alone was not sufficient to inhibit HCC cell proliferation, and the downregulation of Gli-2 decreased both Gli-1 and other target gene expression. These data suggest that Gli-2 may regulate the expression of numerous downstream genes (49). The siRNA-mediated silencing of GLI-2 significantly reduced HCC cell proliferation, therefore, GLI-2 may be a novel target that can be used in the regulation of HCC growth (49).

It has been suggested that activated $\mathrm{Hh}$ signaling may protect human HCC cells from radiotherapy, and that cyclopamine is a potential radiosensitizer $(83,84)$. Shh ligand has been demonstrated to exhibit a protective effect on clonogenic cell survival upon irradiation treatment in HCC cells (84). The combination of irradiation and cyclopamine may be a more effective way to inhibit HCC cell proliferation than using either modality alone. The suppression of cell proliferation by cyclopamine may be attributed to an increase in apoptosis. Radiation upregulates Shh expression in a dose-dependent manner and increases Gli-1 expression in the nucleus (84). Irradiation with cyclopamine treatment could inhibit Gli-1 and increase the breakdown of DNA. In a previous study, when compared with radiotherapy alone, cyclopamine with radiotherapy reduced tumor sizes more effectively. Therefore, radiotherapy with a Shh inhibitor may increase the radio-sensitivity of HCC cells (84). Furthermore, 5-FU treatment may downregulate the expression of Shh signaling and inhibit motility in hedgehog-activated HCC cell lines (85). These results suggest that 5-FU-based chemotherapy with a Shh signaling pathway inhibitor could be a promising treatment option for HCC.

\section{Conclusions and future direction}

HCC is the most common liver malignancy worldwide. Despite advancements in diagnostic methods such as ultrasound, multi-detector computed tomography, magnetic resonance imaging and biomarkers and surgical techniques, the recurrence rates after surgical resection $(57-75 \%)$ or liver transplantation (15-20\%) remain high, and early recurrence decreases the survival rates of patients with HCC $(9,10,86)$. Predicting early recurrence in patients after resection remains a challenge. For patients with a high chance of recurrence, postoperative adjuvant therapies are required. The Shh signaling pathway is highly activated in patients with HCC, affecting hepatocarcinogenesis, HCC progression, cancer stem cell maintenance, invasion and HCC recurrence (Table I). Inhibiting the Shh pathway could therefore be an effective target therapy for HCC treatment.

\section{Acknowledgements}

Not applicable.

\section{Funding}

The current review was supported by grants from The Far Eastern Memorial Hospital (grant nos., FEMH-2017-D-010, FEMH-2018-C-002 and FEMH-2019-C-002), The Far Eastern Memorial Hospital-National Yang-Ming University Joint Research Program (grant nos., 105FN05, 105DN24, 106DN03) and The Ministry of Science and Technology, Taiwan (grant no., MOST 106-2314-B-418-001-MY3).

\section{Availability of data and materials}

Not applicable.

\section{Authors' contributions}

All authors prepared literatures, revised and approved the final manuscript. KSJ, CML, YGT and CFC performed the literature search, wrote/edited the manuscript and prepared the figure and the table. CJJ, WJJ, ISS and SYL contributed to literature review and the conception of the study.

\section{Ethics approval and consent to participate}

Not applicable.

\section{Patient consent for publication}

Not applicable.

\section{Competing interests}

The authors declare that they have no competing interests.

\section{References}

1. Siegel RL, Miller KD and Jemal A: Cancer statistics, 2018. CA: Cancer J Clin 68: 7-30, 2018.

2. Tsai WL and Chung RT: Viral hepatocarcinogenesis. Oncogene 29: 2309-2324, 2010.

3. Arzumanyan A, Reis HM and Feitelson MA: Pathogenic mechanisms in HBV- and $\mathrm{HCV}$-associated hepatocellular carcinoma. Nature reviews. Cancer 13: 123-135, 2013.

4. Stickel F: Alcoholic cirrhosis and hepatocellular carcinoma. Adv Exp Med Biol 815: 113-130, 2015. 
5. Kew MC: Aflatoxins as a cause of hepatocellular carcinoma. J Gastrointestin Liver Dis 22: 305-310, 2013.

6. Di Bisceglie AM: Hepatitis B and hepatocellular carcinoma. Hepatology 49: S56-S60, 2009.

7. Zhu RX, Seto WK, Lai CL and Yuen MF: Epidemiology of Hepatocellular carcinoma in the asia-pacific region. Gut Liver 10: 332-339, 2016

8. Kanda T, Goto T, Hirotsu Y, Moriyama M and Omata M: Molecular mechanisms driving progression of liver cirrhosis towards hepatocellular carcinoma in chronic hepatitis B and C infections: A review. Int J Mol Sci 20: 1358, 2019.

9. Daher S, Massarwa M, Benson AA and Khoury T: Current and future treatment of hepatocellular carcinoma: An updated C omprehensive review. J Clin Transl Hepatol 6: 69-78, 2018.

10. Shindoh J, Hasegawa K, Inoue Y, Ishizawa T, Nagata R, Aoki T, Sakamoto Y, Sugawara Y, Makuuchi M and Kokudo N: Risk factors of post-operative recurrence and adequate surgical approach to improve long-term outcomes of hepatocellular carcinoma. HPB (Oxford) 15: 31-39, 2013.

11. Huang S, He J, Zhang X, Bian Y, Yang L, Xie G, Zhang K, Tang W, Stelter AA, Wang Q, et al: Activation of the hedgehog pathway in human hepatocellular carcinomas. Carcinogenesis 27: 1334-1340, 2006.

12. Della Corte CM, Viscardi G, Papaccio F, Esposito G, Martini G, Ciardiello D, Martinelli E, Ciardiello F and Morgillo F: Implication of the Hedgehog pathway in hepatocellular carcinoma. World J Gastroenterol 23: 4330-4340, 2017

13. Riobo-Del Galdo NA, Lara Montero A and Wertheimer EV: Role of Hedgehog signaling in breast cancer: Pathogenesis and therapeutics. Cells 8: pii: E375, 2019.

14. Pak E and Segal RA: Hedgehog signal transduction: Key players, oncogenic drivers and cancer therapy. Dev Cell 38: 333-344, 2016.

15. Jia Y, Wang Y and Xie J: The Hedgehog pathway: Role in cell differentiation, polarity and proliferation. Arch Toxicol 89: 179-191, 2015

16. Skoda AM, Simovic D, Karin V, Kardum V, Vranic S and Serman L: The role of the Hedgehog signaling pathway in cancer: A comprehensive review. Bosn J Basic Med Sci 18: 8-20, 2018.

17. Bürglin TR: The Hedgehog protein family. Genome Biol 9: 241, 2008.

18. Machado MV and Diehl AM: Hedgehog signalling in liver pathophysiology. J Hepatol 68: 550-562, 2018.

19. Finco I, LaPensee CR, Krill KT and Hammer GD: Hedgehog signaling and steroidogenesis. Annu Rev Physiol 77: 105-129, 2015.

20. Varjosalo M and Taipale J: Hedgehog: Functions and mechanisms. Genes Dev 22: 2454-2472, 2008

21. Stone DM, Hynes M, Armanini M, Swanson TA, Gu Q Johnson RL, Scott MP, Pennica D, Goddard A, Phillips H, et al: The tumour-suppressor gene patched encodes a candidate receptor for Sonic hedgehog. Nature 384: 129-134, 1996.

22. Hanna A and Shevde LA: Hedgehog signaling: Modulation of cancer properies and tumor mircroenvironment. Mol Cancer 15: 24, 2016.

23. Ramsbottom SA and Pownall ME: Regulation of Hedgehog signalling inside and outside the cell. J Dev Biol 4: 23, 2016.

24. Pham A, Therond P, Alves G, Tournier FB, Busson D, Lamour-Isnard C, Bouchon BL, Préat T and Tricoire H: The Suppressor of fused gene encodes a novel PEST protein involved in Drosophila segment polarity establishment. Genetics 140: 587-598, 1995

25. Zhang Z, Shen L, Law K, Zhang Z, Liu X, Hua H, Li S, Huang H, Yue S, Hui CC and Cheng SY: Suppressor of fused chaperones gli proteins to generate transcriptional responses to sonic Hedgehog signaling. Mol Cell Biol 37: e00421-00416, 2017.

26. Niewiadomski P, Niedziółka SM, Markiewicz Ł, Uśpieński T, Baran B and Chojnowska K: Gli proteins: Regulation in development and cancer. Cells 8: 147, 2019.

27. Katoh Y and Katoh M: Hedgehog target genes: Mechanisms of carcinogenesis induced by aberrant hedgehog signaling activation. Curr Mol Med 9: 873-886, 2009.

28. Che L, Yuan YH, Jia J and Ren J: Activation of sonic hedgehog signaling pathway is an independent potential prognosis predictor in human hepatocellular carcinoma patients. Chin J Cancer Res 24: 323-331, 2012.

29. Jeng KS, Sheen IS, Jeng WJ, Lin CC, Lin CK, Su JC, Yu MC and Fang HY: High expression of patched homolog-1 messenger RNA and glioma-associated oncogene-1 messenger RNA of sonic hedgehog signaling pathway indicates a risk of postresection recurrence of hepatocellular carcinoma. Ann Surg Oncol 20 464-473, 2013
30. Dugum M, Hanouneh I, McIntyre T, Pai R, Aucejo F, Eghtesad B and Zein N: Sonic hedgehog signaling in hepatocellular carcinoma: A pilot study. Mol Clin Oncol 4: 369-374, 2016.

31. Zhang D, Cao L, Li Y, Lu H, Yang X and Xue P: Expression of glioma-associated oncogene 2 (Gli 2) is correlated with poor prognosis in patients with hepatocellular carcinoma undergoing hepatectomy. World J Surg Oncol 11: 25, 2013.

32. Sicklick JK, Li YX, Jayaraman A, Kannangai R, Qi Y, Vivekanandan P, Ludlow JW, Owzar K, Chen W, Torbenson MS and Diehl AM: Dysregulation of the Hedgehog pathway in human hepatocarcinogenesis. Carcinogenesis 27: 748-757, 2006.

33. Cheng WT, Xu K, Tian DY, Zhang ZG, Liu LJ and Chen Y: Role of Hedgehog signaling pathway in proliferation and invasiveness of hepatocellular carcinoma cells. Int J Oncol 34: 829-836, 2009.

34. Tarocchi M, Polvani S, Marroncini G and Galli A: Molecular mechanism of hepatitis B virus-induced hepatocarcinogenesis. World J Gastroenterol 20: 11630-11640, 2014

35. Arzumanyan A, Sambandam V, Clayton MM, Choi SS, Xie G, Diehl AM, Yu DY and Feitelson MA: Hedgehog signaling blockade delays hepatocarcinogenesis induced by hepatitis B virus X protein. Cancer Res 72: 5912-5920, 2012.

36. Pereira Tde A, Witek RP, Syn WK, Choi SS, Bradrick S, Karaca GF, Agboola KM, Jung Y, Omenetti A, Moylan CA, et al: Viral factors induce Hedgehog pathway activation in humans with viral hepatitis, cirrhosis and hepatocellular carcinoma. Lab Invest 90: 1690-1703, 2010.

37. Choi SS, Bradrick S, Qiang G, Mostafavi A, Chaturvedi G, Weinman SA, Diehl AM and Jhaveri R: Up-regulation of Hedgehog pathway is associated with cellular permissiveness for hepatitis C virus replication. Hepatology 54: 1580-1590, 2011.

38. Wang Y, Chen W, Han C, Zhang J, Song K, Kwon H, Dash S, Yao L and Wu T: Adult hepatocytes are hedgehog-responsive cells in the setting of liver injury: Evidence for smoothened-mediated activation of NF-kappaB/epidermal growth factor receptor/Akt in hepatocytes that counteract fas-induced apoptosis. Am J Pathol 188: 2605-2616, 2018.

39. He G and Karin M: NF- $\mathrm{BB}$ and STAT3-key players in liver inflammation and cancer. Cell Res 21: 159-168, 2011

40. Mills LD, Zhang Y, Marler RJ, Herreros-Villanueva M, Zhang L, Almada LL, Couch F, Wetmore C, Pasca di Magliano M and Fernandez-Zapico ME: Loss of the transcription factor GLI1 identifies a signaling network in the tumor microenvironment mediating KRAS oncogene-induced transformation. J Biol Chem 288: 11786-11794, 2013.

41. Sarangi A, Valadez JG, Rush S, Abel TW, Thompson RC and Cooper MK: Targeted inhibition of the Hedgehog pathway in established malignant glioma xenografts enhances survival. Oncogene 28: 3468-3476, 2009.

42. Adolphe C, Hetherington R, Ellis T and Wainwright B: Patched functions as a gatekeeper by promoting cell cycle progression. Cancer Res 66: 2081-2088, 2006.

43. Hasanovic A and Mus-Veteau I: Targeting the multidrug transporter ptch1 potentiates chemotherapy efficiency. Cells 7: pii: E107, 2018.

44. Ding X, Yang Y, Han B, Du C, Xu N, Huang H, Cai T, Zhang A, Han ZG, Zhou W and Chen L: Transcriptomic characterization of hepatocellular carcinoma with CTNNB1 mutation. PLoS One 9: e95307, 2014

45. Efroni S, Meerzaman D, Schaefer CF, Greenblum S, Soo-Lyu M, $\mathrm{Hu}$ Y, Cultraro C, Meshorer E and Buetow KH: Systems analysis utilising pathway interactions identifies sonic hedgehog pathway as a primary biomarker and oncogenic target in hepatocellular carcinoma. IET Syst Biol 7: 243-251, 2013.

46. Chung SI, Moon H, Ju HL, Cho KJ, Kim DY, Han KH, Eun JW, Nam SW, Ribback S, Dombrowski F, et al: Hepatic expression of Sonic Hedgehog induces liver fibrosis and promotes hepatocarcinogenesis in a transgenic mouse model. J Hepatol 64: 618-627, 2016.

47. Cai H, Li H, Li J, Li X, Li Y, Shi Y and Wang D: Sonic hedgehog signaling pathway mediates development of hepatocellular carcinoma. Tumour Biol: Oct 15, 2016 (Epub ahead of print).

48. Michelotti GA, Xie G, Swiderska M, Choi SS, Karaca G, Krüger L, Premont R, Yang L, Syn WK, Metzger D and Diehl AM: Smoothened is a master regulator of adult liver repair. J Clin Invest 123: 2380-2394, 2013.

49. Kim Y, Yoon JW, Xiao X, Dean NM, Monia BP and Marcusson EG: Selective down-regulation of glioma-associated oncogene 2 inhibits the proliferation of hepatocellular carcinoma cells. Cancer Res 67: 3583-3593, 2007. 
50. Lu JT, Zhao WD, He W and Wei W: Hedgehog signaling pathway mediates invasion and metastasis of hepatocellular carcinoma via ERK pathway. Acta Pharmacol Sin 33: 691-700, 2012.

51. Wang YH, Sui XM, Sui YN, Zhu QW, Yan K, Wang LS, Wang F and Zhou JH: BRD4 induces cell migration and invasion in HCC cells through MMP-2 and MMP-9 activation mediated by the Sonic hedgehog signaling pathway. Oncol Lett 10: 2227-2232, 2015.

52. Xu Q, Liu X, Zheng X, Yao Y, Wang M and Liu Q: The transcriptional activity of Gli1 is negatively regulated by AMPK through Hedgehog partial agonism in hepatocellular carcinoma. Int J Mol Med 34: 733-741, 2014.

53. Matsuo N, Shiraha H, Fujikawa T, Takaoka N, Ueda N, Tanaka S, Nishina S, Nakanishi Y, Uemura M, Takaki A, et al: Twist expression promotes migration and invasion in hepatocellular carcinoma. BMC Cancer 9: 240, 2009.

54. Meng J, Chen S, Han JX, Qian B, Wang XR, Zhong WL, Qin Y, Zhang $\mathrm{H}$, Gao WF, Lei YY, et al: Twistl regulates vimentin through Cul2 circular RNA to promote EMT in hepatocellular carcinoma. Cancer Res 78: 4150-4162, 2018.

55. Chun HW and Hong R: Significance of the hedgehog pathway-associated proteins Gli-1 and Gli-2 and the epithelial-mesenchymal transition-associated proteins Twist and E-cadherin in hepatocellular carcinoma. Oncol Lett 12: 1753-1762, 2016

56. Chen JS, Huang XH, Wang Q, Huang JQ, Zhang LJ, Chen XL, Lei J and Cheng ZX: Sonic hedgehog signaling pathway induces cell migration and invasion through focal adhesion kinase/AKT signaling-mediated activation of matrix metalloproteinase (MMP)-2 and MMP-9 in liver cancer. Carcinogenesis 34: 10-19, 2013.

57. Zeller C, Hinzmann B, Seitz S, Prokoph H, Burkhard-Goettges E, Fischer J, Jandrig B, Schwarz LE, Rosenthal A and Scherneck S: SASH1: A candidate tumor suppressor gene on chromosome $6 \mathrm{q} 24.3$ is downregulated in breast cancer. Oncogene 22: 2972-2983, 2003.

58. He P,Zhang HX, Sun CY, Chen CY and Jiang HQ: Overexpression of SASH1 inhibits the proliferation, invasion and EMT in hepatocarcinoma cells. Oncol Res 24: 25-32, 2016.

59. Sun $C$, Zhang $Z$, He P, Zhou $Y$ and $X i e X$ : Involvement of $\mathrm{PI} 3 \mathrm{~K} / \mathrm{Akt}$ pathway in the inhibition of hepatocarcinoma cell invasion and metastasis induced by SASH1 through downregulating Shh-Gli1 signaling. Int J Biochem Cell Biol 89: 95-100, 2017.

60. Kitagawa $\mathrm{H}$, Uyama $\mathrm{T}$ and Sugahara $\mathrm{K}$ : Molecular cloning and expression of a human chondroitin synthase. J Biol Chem 276: 38721-38726, 2001.

61. Tian J, Ling L, Shboul M, Lee H, O'Connor B, Merriman B, Nelson SF, Cool S, Ababneh OH, Al-Hadidy A, et al: Loss of CHSY1, a secreted FRINGE enzyme, causes syndromic brachydactyly in humans via increased NOTCH signaling. Am J Hum Genet 87: 768-778, 2010.

62. Liu CH, Lan CT, Chou JF, Tseng TJ and Liao WC: CHSY1 promotes aggressive phenotypes of hepatocellular carcinoma cells via activation of the hedgehog signaling pathway. Cancer Lett 403: 280-288, 2017.

63. Merchant AA and Matsui W: Targeting Hedgehog-a cancer stem cell pathway. Clin Cancer Res 16: 3130-3140, 2010.

64. Jeng KS, Sheen IS, Jeng WJ, Yu MC, Hsiau HI, Chang FY and Tsai HH: Activation of the sonic hedgehog signaling pathway occurs in the CD133 positive cells of mouse liver cancer Hepa 1-6 cells. Onco Targets Ther 6: 1047-1055, 2013.

65. Abou-Shady M, Baer HU, Friess H, Berberat P, Zimmermann A, Graber H, Gold LI, Korc M and Büchler MW: Transforming growth factor betas and their signaling receptors in human hepatocellular carcinoma. Am J Surg 177: 209-215, 1999.

66. Fabregat I and Caballero-Diaz D: Transforming growth factor-beta-induced cell plasticity in liver fibrosis and Hepatocarcinogenesis. Front Oncol 8: 357, 2018.

67. Steinway SN, Zañudo JG, Ding W, Rountree CB, Feith DJ, Loughran TP Jr and Albert R: Network modeling of TGFbeta signaling in hepatocellular carcinoma epithelial-to-mesenchymal transition reveals joint sonic hedgehog and Wnt pathway activation. Cancer Res 74: 5963-5977, 2014.

68. Javelaud D, Alexaki VI, Dennler S, Mohammad KS, Guise TA and Mauviel A: TGF- $/$ /SMAD/GLI2 signaling axis in cancer progression and metastasis. Cancer Res 71: 5606-5610, 2011.
69. Fan Q, He M, Sheng T, Zhang X, Sinha M, Luxon B, Zhao X and Xie J: Requirement of TGFbeta signaling for SMO-mediated carcinogenesis. J Biol Chem 285: 36570-36576, 2010.

70. Katoh Y and Katoh M: Hedgehog signaling, epithelial-to-mesenchymal transition and miRNA (Review). Int J Mol Med 22: 271-275, 2008

71. Giakoustidis A, Giakoustidis D, Mudan S, Sklavos A and Williams R: Molecular signalling in hepatocellular carcinoma: Role of and crosstalk among WNT/ss-catenin, Sonic Hedgehog, Notch and Dickkopf-1. Can J Gastroenterol Hepatol 29: 209-217, 2015.

72. Chong YC, Lim TE, Fu Y, Shin EM, Tergaonkar V and Han W: Indian Hedgehog links obesity to development of hepatocellular carcinoma. Oncogene 38: 2206-2222, 2019.

73. Tripathy A, Thakurela S, Sahu MK, Uthanasingh K, Behera M, Ajay AK and Kumari R: The molecular connection of histopathological heterogeneity in hepatocellular carcinoma: A role of Wnt and Hedgehog signaling pathways. PLoS One 13: e0208194, 2018.

74. Salaritabar A, Berindan-Neagoe I, Darvish B, Hadjiakhoondi F, Manayi A, Devi KP, Barreca D, Orhan IE, Süntar I, Farooqi AA, et al: Targeting Hedgehog signaling pathway: Paving the road for cancer therapy. Pharmacol Res 141: 466-480, 2019.

75. Dijkgraaf GJ, Alicke B, Weinmann L, Januario T, West K, Modrusan Z, Burdick D, Goldsmith R, Robarge K, Sutherlin D, et al: Small molecule inhibition of GDC-0449 refractory smoothened mutants and downstream mechanisms of drug resistance. Cancer Res 71: 435-444, 2011.

76. Chen JK, Taipale J, Cooper MK and Beachy PA: Inhibition of Hedgehog signaling by direct binding of cyclopamine to Smoothened. Genes Dev 16: 2743-2748, 2002.

77. Jeng KS, Sheen IS, Jeng WJ, Yu MC, Tsai HH, Chang FY and Su JC: Blockade of the sonic hedgehog pathway effectively inhibits the growth of hepatoma in mice: An in vivo study. Oncol Lett 4: 1158-1162, 2012.

78. Jeng KS, Jeng CJ, Jeng WJ, Sheen IS, Chang CF, Hsiau HI, Hung ZH, Yu MC and Chang FY: Sonic hedgehog pathway inhibitor mitigates mouse hepatocellular carcinoma. Am J Surg 210: 554-560, 2015.

79. Sun Y, Guo W, Ren T, Liang W, Zhou W, Lu Q, Jiao G and Yan T: Glil inhibition suppressed cell growth and cell cycle progression and induced apoptosis as well as autophagy depending on ERK1/2 activity in human chondrosarcoma cells. Cell Death Dis 5: e979, 2014.

80. Wang Y, Han C, Lu L, Magliato S and Wu T: Hedgehog signaling pathway regulates autophagy in human hepatocellular carcinoma cells. Hepatology 58: 995-1010, 2013.

81. Lin TL and Matsui W: Hedgehog pathway as a drug target: Smoothened inhibitors in development. Onco Targets Ther 5: $47-58,2012$

82. Wu X, Zhao B, Cheng Y, Yang Y, Huang C, Meng X, Wu B, Zhang L, Lv X and Li J: Melittin induces PTCH1 expression by down-regulating MeCP2 in human hepatocellular carcinoma SMMC-7721 cells. Toxicol Appl Pharmacol 288: 74-83, 2015

83. Chen YJ, Lin CP, Hsu ML, Shieh HR, Chao NK and Chao KS: Sonic hedgehog signaling protects human hepatocellular carcinoma cells against ionizing radiation in an autocrine manner. Int J Radiat Oncol Biol Phys 80: 851-859, 2011

84. Tsai CL, Hsu FM, Tzen KY, Liu WL, Cheng AL and Cheng JC: Sonic Hedgehog inhibition as a strategy to augment radiosensitivity of hepatocellular carcinoma. J Gastroenterol Hepatol 30: 1317-1324, 2015.

85. Wang Q, Huang S, Yang L, Zhao L, Yin Y, Liu Z, Chen Z and Zhang H: Down-regulation of Sonic hedgehog signaling pathway activity is involved in 5-fluorouracil-induced apoptosis and motility inhibition in Hep3B cells. Acta Biochim Biophys Sin (Shanghai) 40: 819-829, 2008.

86. Filgueira NA: Hepatocellular carcinoma recurrence after liver transplantation: Risk factors, screening and clinical presentation. World J Hepatol 11: 261-272, 2019.

This work is licensed under a Creative Commons

Attribution-NonCommercial-NoDerivatives 4.0 International (CC BY-NC-ND 4.0) License. 